\title{
Portfolio Optimization of Some Stocks on the Ghana Stock Exchange Using the Markowitz Mean-Variance Approach
}

\author{
Anuwoje Ida Logubayom, Togborlo Annani Victor \\ Department of Statistics, Faculty of Mathematical Sciences, University for Development Studies, Tamale, Ghana \\ Email: ilogubayom@uds.edu.gh
}

How to cite this paper: Logubayom, A. I., \& Victor, T. A. (2019). Portfolio Optimization of Some Stocks on the Ghana Stock Exchange Using the Markowitz Mean-Variance Approach. Journal of Financial Risk Management, 8, 29-41.

https://doi.org/10.4236/jfrm.2019.81003

Received: February 11, 2019

Accepted: March 19, 2019

Published: March 22, 2019

Copyright ( 2019 by author(s) and Scientific Research Publishing Inc. This work is licensed under the Creative Commons Attribution International License (CC BY 4.0).

http://creativecommons.org/licenses/by/4.0/

\begin{abstract}
An investment portfolio is a collection of financial assets consisting of investment tools such as stocks, bonds, and bank deposits, among others, which are held by a person or a group of persons. Constructing a portfolio with standardized optimization remains a myth in Ghana and hence this study displayed how the Markowitz model can be applied on the Ghana Stock Exchange and also unraveled the most efficient portfolio among selected stocks to the relief of the investor. Historical monthly data of the stock returns from 2011 to 2016 was used for the study. The study revealed that, GCB Bank limited had the best average returns (returns of $4.2 \%$ ) with a risk of $13.1 \%$ followed by CAL (returns of 3.5\%) and 11.7\% risk. UGL had the lowest risk (risk of $6.8 \%$ ) and lowest average returns of $2.1 \%$. A risk lover may go in for GCB and CAL while an investor who is completely risk averse can opt for UGL since it comes with the lowest risk. A two-way combination of the portfolios also concluded that, the most efficient portfolio is the combination of GCB and CAL and recommended that a risk tolerant investor can invest all his assets in GCB while a risk averse investor can invest $39.21 \%$ of his assets in GCB and $60.79 \%$ in CAL. In terms of expected returns, a combination of CAL and GCB bank limited gives the highest returns of about 3.9\% with a risk of $10.6 \%$, followed by the combination of TOTAL and GCB with expected returns of about $3.40 \%$ and a high risk of $12.3 \%$. The relatively high expected return of the combination of TOTAL and GCB could not reflect in the Sharpe ratio because of the high level of risk which implies that the portfolio cannot compensate much for this high level of risk. Also, CAL and GCB achieving the highest Sharpe ratio shows that, this portfolio is expected to offer the best compensation for the risk taken by an investor and therefore the most efficient portfolio for investor. The lowest risk (which is what the risk averse investor is interested in) was achieved from the combination of HFC and UGL
\end{abstract}


which is $5.2 \%$ with a Sharpe ratio of $6.7 \%$ and a covariance of -0.00051 .

\section{Keywords}

Portfolio Optimization, Mean-Variance, Variance-Covariance Matrix

\section{Introduction}

Investment activity is essential to the promotion of economic well-being; it is one of the most important economic activities that individuals, businesses and governments undertake. The commitment of resources in anticipation that an affirmative rate of return will be achieved is known as investment (Mensah, 2008). Major considerations when investing include what to invest in, how much to invest and the level of risk an investor is prepared to bear in order to achieve his/her investment goal. A portfolio is simply a collection of financial assets involving investment tools such as bonds, foreign exchange, stocks, gold, asset-backed securities, real estate certificates and bank deposits which are held simultaneously by one person or a group of persons.

Risk is the probability of the losses one incurred on portfolio investment whiles the return is the profit or benefit one derives from portfolio investment. Investment is the net worth on long term financial assets such as bonds, shares and mutual funds. Investment risk is most properly understood when it is expressed in statistical terms that consider the entire range of an investment's possible returns. Markowitz states that, the expected return (mean) and variance and standard deviation (risk) of a portfolio are the whole criteria for portfolio selection and construction. These parameters can be used as a possible maxim for how investors need to act. It is interesting to note that, the whole model is based on an economic fact of "Expected Utility". The concept of utility here is based on the fact that different investors have different investment goals and can be satisfied in different ways.

The theory of portfolio optimization is generally associated with the classical mean-variance optimization framework of Markowitz (Markowitz, 1952). The drawback of the mean-variance analysis is mainly related to its sensitivity to the estimation error of the means and covariance matrix estimation of the returns of the asset. Also, it is argued that estimates of the covariance matrix are more accurate than those of the expected returns (Merton, 1980; Jagannathan \& Ma, 2003). Several studies concentrates on improving the performance of the global minimum-variance portfolio (GMVP), which provides the least possible portfolio risk and involves only the covariance matrix estimates. The classical mean-variance framework depends on the perfect knowledge of the expected returns of the assets and their variance-covariance matrix. However, these returns are unobservable and unknown. The impossibility to obtain a sufficient number of data samples, instability of data, and differing personal views of decision makers on the 
future returns affect their estimation and have led to what call estimation risk in portfolio selection (Mulvey \& Erkan, 2003; Bawa, Brown, \& Klein, 1979). This estimation risk has shown to be the source of very erroneous decisions; as pointed in (Ceria \& Stubbs, 2006; Cornuejols \& Tutuncu, 2007), the composition of the optimal portfolio is very sensitive to the mean and the covariance matrix of the asset returns and agitation in the moments of the random returns can result in the difficulties in constructing different optimization.

Consequently, every investor seeks to maximize their utility (satisfaction) by maximizing expected return and minimizing risk (variance). The Markowitz model could be summarized as follows; Calculate the expected return rates for each stock to be included in the portfolio; Calculate the variance or standard deviation (risk) for each stock to be included in the portfolio; Calculate the co-variance or correlation coefficients for all stocks, treating them as pairs (Fabozzi, 1999).

\section{Methods of Data Analysis}

\subsection{Data Collection Methods}

Secondary data on the monthly returns of selected companies on the Ghana Stock Exchange was collected from the Ghana Stock Exchange database ranging from 2011 to 2016.

\subsection{Mathematics of the Markowitz Mean-Variance Model}

The Markowitz model involves some mathematics, which makes it possible to construct stock portfolio with different combinations where short sale and lending or borrowing might be allowed or not. The Markowitz model is all about maximizing return, and minimizing risk, but simultaneously. We should be able reach a single portfolio of risky assets with the least possible risk that is preferred to all other portfolio with the same level of return. Our optimal portfolio will be somewhere on the ray connecting risk free investment to our risky portfolio and where the ray becomes tangent to our set of risky portfolios. This point has the highest possible slope. In mathematics, optimization refers to the selection of a best element, with regard to certain conditions, from a set of possible alternatives.

\subsection{Different Approaches for Portfolio Optimization}

Even in Mean-Variance framework, there are different approaches when it comes to searching for optimum portfolio of risky asset. In the following lines we will introduce three different approaches, based either on desired expected return and risk or on finding the portfolio with highest reward-to-risk ratio.

\section{Optimum Portfolio for Particular Rate of Return}

When investor wants to construct a portfolio which yields a particular rate of return and simultaneously minimize the portfolio risk, he is facing a linear programming problem in a form: 


$$
\begin{gathered}
\operatorname{Min} W^{\mathrm{T}} \Sigma W \\
\text { ST. } r_{p}(W) \geq \mu \Lambda W_{i} \geq 0 \Lambda W^{\mathrm{T}} e=1
\end{gathered}
$$

where $e$ is column vector of ones, i.e. $e=[1,1, \cdots, 1]^{\mathrm{T}}$, and $\mu$ is desired rate of return.

\section{Optimum Portfolio for Particular Risk Rate}

Another approach for finding optimum portfolio of risky assets is to set a desired level of portfolio risk and find a combination of securities, which maximize expected return. This process can be once again formulated in terms of linear programming problem, as:

$$
\begin{gathered}
\operatorname{Max} r_{p}(W) \\
S T . \quad W^{\mathrm{T}} \Sigma W \leq \sigma \Lambda W_{i} \geq 0 \Lambda W^{\mathrm{T}} e=1
\end{gathered}
$$

where $\sigma$ is level of portfolio variance, which should not be exceeded.

Similarly, to the first approach, we will arrive to efficient frontier by changing the value of $\sigma$. Moreover, it has been proved by (Palmquist, Pavlo, \& Uryasev, 2002) that, by these optimization approaches we will arrive at the same results. Thus, we obtain the identical efficient frontier in both cases.

\section{Optimum Portfolio Dependent on Risk Aversion Parameter}

There is still a third way how to arrive to the efficient frontier. We can consider a problem proposed by (Sharpe, 1994).

$$
\begin{gathered}
\operatorname{Min}-\lambda * E(r)^{\mathrm{T}} W+W^{\mathrm{T}} \Sigma W \\
S T . W_{i} \geq 0 \\
W^{\mathrm{T}} e=1
\end{gathered}
$$

where $\lambda$ is risk aversion parameter. By varying $\lambda$ one can arrive to the same efficient frontier as in two previous cases.

\subsection{Assumptions of the Markowitz Mean-Variance Model}

The Markowitz model has the following assumptions:

1) That an investor is apprehensive with return distribution over a single period.

2) Investors try to maximize the expected return of total wealth.

3) All investors are risk-averse, i.e. they will simply take a higher risk if they are rewarded for higher expected return.

4) Investors based their investment judgments on the expected return and risk.

5) All markets are perfectly effective.

6) Investments are also by a single period. This means that, investors make their portfolio decisions at the start of a period and then wait until the close of the period when the rate of return on their portfolio is realized. Also the investor cannot make any intermediate changes in the composition of his portfolio; and finally the investor makes his choice with the aim of maximizing expected utility 
of wealth at the end of the period (final wealth).

The Markowitz approach is often described as a mean-variance method since; it simply takes those two parameters, mean return and variance of return into consideration to characterize the investor's portfolio. The expected return of the portfolio is quantified by the mean return, while the risk of the portfolio is measured by the variance. The variance facilitates simple modeling and also is a good measure of risk under the supposition that returns are normally distributed. The concept established by Markowitz is also centered on maximizing the expected utility of the investor's terminal fortune. The utility function is defined according to the expected return and the standard deviation of the wealth.

\subsection{The Sharpe's Ratio}

This ratio is a measurement for risk-adjusted returns and was developed by William F. Sharpe.

There is a risk and return characteristics of the portfolio that will change in a non-linear fashion as the weighting of the component assets change. The Sharpe ratio characterizes how well the return of an asset compensates the investor for the risk taken. The higher the returns mean better investment option.

$$
S p=\frac{\text { risk premium }}{\text { systematic risk }}=\frac{r_{p}-R}{{ }^{\delta} p}
$$

where

$r_{p}$ is the average returns of portfolio $p$,

$R$ is the risk-free rate of returns,

${ }^{\delta} p$ is the standard deviation (risk) of portfolio $p$.

\subsection{Risk and Return}

The expected returns of portfolio $p=r_{p}(W)=W^{\mathrm{T}} E(r)$.

$w$ denotes the vector of the portfolio weights and the $E(r)$ denotes the vector of the expected returns of the portfolio instruments.

$$
\text { Variance } p(w)=w^{\mathrm{T}} \Sigma W
$$

where $w$ denotes the vector of portfolio weights and $\Sigma$ denotes the variance-covariance matrix

$$
\text { Risk }(\text { standard deviation })=\rho_{p}(W)=\sqrt{W^{\mathrm{T}} \Sigma W}
$$

where $\rho$ denotes the risk of the portfolio.

\section{Results and Discussion}

\section{Statistical Estimation for Each Asset}

Table 1 presents the six-year period of mean return and standard deviation, the skewness and the kurtosis of the individual assets. Skewness is used in statistics to describe asymmetry from the normal distribution in a set of statistical data. 
Table 1. Risk, return, skewness and kurtosis of assets.

\begin{tabular}{ccccc}
\hline STOCK & ST. DEV & RETURNS & SKEWNESS & KURTOSIS \\
\hline CAL & 0.117 & 0.035 & 0.857 & 1.033 \\
EBG & 0.088 & 0.02 & 1.182 & 1.629 \\
GCB & 0.131 & 0.043 & 1.667 & 5.18 \\
SCB & 0.152 & 0.016 & -2.586 & 18.308 \\
HFC & 0.084 & 0.016 & 1.908 & 6.542 \\
UGL & 0.069 & 0.022 & 0.067 & 2.495 \\
GGL & 0.093 & 0.019 & -1.023 & 4.412 \\
FMGL & 0.137 & 0.013 & -2.827 & 18.561 \\
PZC & 0.167 & 0.003 & -0.98 & 12.901 \\
TOTAL & 0.166 & 0.025 & -2.301 & 15.405 \\
\hline
\end{tabular}

Skewness can come in the form of negative skewness or positive skewness, depending on whether data points are skewed to the left and negative, or to the right and positive of the data average. For a positively skewed data, the mean and the median of the set are both greater than the mode and in most cases, the mean is greater than the median. Thus average higher returns will be obtained for such an investment. Conversely, when data are skewed to the left, the mean and the median are both less than the mode and the mean possibly less than the median. A skewed data indicate deviation from normality. By understanding which way data is skewed, an investor can better estimate whether a given future data point will be more or less than the mean. Many casual equity investors look at the chart of a stock's price and try to make investments in companies that are positively skew, which in the equity markets is a stock price that is greatly skewed positively with possible higher average returns. From the results, the potentially great fortune of GCB can be seen with its positive skewness of 1.667 as it is the second highest behind HFC (with 1.908 skewness) indicating possible higher gains. SCB, GGL, FMGL, PZC and TOTAL yielded negative skewness which indicates losses while the rest of the stocks had positive skewness indicating gains. Kurtosis is a measure of the likelihood that an event occurring is extreme in relation to a given distribution and is often referred to as the volatility. The higher the kurtosis coefficient is above the normal level (which is 3), the more volatile the future return (thus either extremely large or extremely small). CAL, EBG and UGL had kurtosis lesser than 3 (they are platykurtic) while the others had kurtosis greater than 3 (are leptokurtic). SCH, FMGL, PZC and TOTAL had kurtosis of 18.308, 18.561, 12.901 and 15.405 respectively which are far above the normal level (3) and imply a high likelihood of their future returns being either extremely large or extremely small.

By investing solely in one of the ten assets, it is not possible to achieve a return more desirable than the asset itself. An investor would prefer a risk/return relationship yielding a high return associated with low risk; however this is not 
possible due to the fact that high return almost always comes with high risk. By constructing a portfolio of the assets, the author strives to reach a return more desirable than any of the assets themselves, a combined portfolio with a minimized risk and a more desirable return.

From the ten companies selected, we considered two-asset portfolio. This yielded 45 possible combinations out of which the most efficient portfolio had to be determined. To do this, equal weights were assigned to each combination to determine the Sharpe Ratio of each of the combinations. The Sharpe ratio tells how well the return of assets compensates for the risk taken and hence the higher the ratio, the better the portfolio.

The highest Sharpe Ratio obtained would belong to the best combination as it represents the best combination with the best excess return over the risk of each portfolio. Table 2 gives the 45 asset combinations with their returns, risk and Sharpe Ratios. From Table 2, the highest Sharpe ratio is ascertained from the combination of CAL and GCB. This portfolio yielded a Sharpe ratio of about 21.6 with a risk of $10.6 \%$ and a covariance of 0.007089 . This positive covariance implies that both assets move in the same direction. Thus, whenever there is an increase (or a decrease) in the returns of CAL, the returns of GCB also experience an increase (or decrease). CAL and GCB achieving the highest Sharpe ratio implies that, it is the portfolio which is expected to offer the best compensation for the risk taken by an investor and therefore the most efficient portfolio for a rational investor to opt for. In terms of expected returns, the combination of CAL and GCB had the highest of about 3.9\% with a risk of $10.6 \%$ followed by the combination of TOTAL and GCB with expected returns of about $3.40 \%$ and a high risk of $12.3 \%$. The relatively high expected return of the combination of TOTAL and GCB could not reflect in is Sharpe ratio because of the high level of risk which implies that the portfolio cannot compensate much for this high level of risk. Also, the lowest risk (which is what the risk averse investor is interested in) was achieved from the combination of HFC and UGL which is $5.2 \%$ with a Sharpe ratio of $6.7 \%$ and a covariance of -0.00051 . The negative covariance implies that the two assets move in opposite directions. Thus, when one is experiencing an increase in returns, the other is experiencing a decrease in returns. However, the covariance only shows directional relationship between two assets but cannot show the strength of the relationship. It is also sensitive to high volatility (volatile assets include those with returns that are farther from the mean) and hence correlation coefficients is a better measure.

The correlation coefficients show the strength of the relationships between the companies or it measures the extent to which there is a linear relationship between the two assets. The correlation between two assets may be negative (correlation, $-1 \leq \rho<0)$, positive (correlation, $0<\rho \leq 1)$, no correlation $(\rho=0)$. There is a perfect positive/negative if correlation coefficient of 1 or -1 respectively. Whenever there exists a perfectly positive correlation between two assets, there is no need to diversify because it does not reduce the unsystematic risk whereas a perfectly negative correlation (a correlation coefficient of -1 ) between 
Table 2. Optimum portfolio combinations.

\begin{tabular}{|c|c|c|c|c|}
\hline $\begin{array}{c}\text { ASSET } \\
\text { COMBINATIONS }\end{array}$ & $\begin{array}{c}\text { PORTFOLIO } \\
\text { RETURNS }\end{array}$ & $\begin{array}{l}\text { PORTFOLIO } \\
\text { COVARIANCE }\end{array}$ & $\begin{array}{c}\text { PORTFOLIO } \\
\text { RISK }\end{array}$ & $\begin{array}{l}\text { PORTFOLIO } \\
\text { SHARPE RATIO }\end{array}$ \\
\hline CAL-EBG & 0.027 & 0.000 & 0.074 & 0.159 \\
\hline CAL-GCB & 0.039 & 0.007 & 0.106 & 0.216 \\
\hline CAL-SCB & 0.025 & -0.001 & 0.094 & 0.101 \\
\hline CAL-HFC & 0.025 & 0.000 & 0.072 & 0.136 \\
\hline CAL-UGL & 0.028 & 0.001 & 0.070 & 0.179 \\
\hline CAL-GGL & 0.027 & 0.004 & 0.086 & 0.131 \\
\hline CAL-FMGL & 0.024 & -0.003 & 0.082 & 0.096 \\
\hline CAL-PZC & 0.019 & 0.001 & 0.105 & 0.030 \\
\hline CAL-TOTAL & 0.030 & 0.003 & 0.109 & 0.130 \\
\hline EBG-GCB & 0.032 & 0.000 & 0.080 & 0.198 \\
\hline EBG-SCB & 0.018 & 0.003 & 0.096 & 0.025 \\
\hline EBG-HFC & 0.018 & 0.002 & 0.067 & 0.041 \\
\hline EBG-UGL & 0.021 & 0.001 & 0.059 & 0.093 \\
\hline EBG-GGL & 0.020 & 0.001 & 0.066 & 0.064 \\
\hline EBG-FMGL & 0.016 & 0.000 & 0.081 & 0.010 \\
\hline EBG-PZC & 0.012 & 0.001 & 0.096 & -0.041 \\
\hline EBG-TOTAL & 0.023 & 0.001 & 0.097 & 0.073 \\
\hline GCB-SCB & 0.029 & 0.000 & 0.101 & 0.134 \\
\hline GCB-HFC & 0.030 & 0.000 & 0.078 & 0.179 \\
\hline GCB-UGL & 0.032 & 0.003 & 0.082 & 0.202 \\
\hline GCB-GGL & 0.031 & 0.004 & 0.092 & 0.167 \\
\hline GCB-FMGL & 0.028 & 0.005 & 0.106 & 0.113 \\
\hline GCB-PZC & 0.023 & 0.003 & 0.114 & 0.064 \\
\hline GCB-TOTAL & 0.034 & 0.008 & 0.123 & 0.149 \\
\hline SCB-HFC & 0.016 & 0.001 & 0.089 & 0.005 \\
\hline SCB-UGL & 0.019 & 0.001 & 0.087 & 0.036 \\
\hline SCB-GGL & 0.018 & 0.000 & 0.089 & 0.022 \\
\hline SCB-FMGL & 0.014 & 0.003 & 0.108 & -0.013 \\
\hline SCB-PZC & 0.009 & 0.001 & 0.114 & -0.055 \\
\hline SCB-TOTAL & 0.020 & 0.000 & 0.112 & 0.043 \\
\hline HFC-UGL & 0.019 & -0.001 & 0.052 & 0.068 \\
\hline HFC-GGL & 0.018 & 0.001 & 0.067 & 0.034 \\
\hline HFC-FMGL & 0.015 & 0.002 & 0.087 & -0.013 \\
\hline HFC-PZC & 0.010 & 0.001 & 0.095 & -0.062 \\
\hline HFC-TOTAL & 0.021 & 0.001 & 0.096 & 0.054 \\
\hline
\end{tabular}




\begin{tabular}{ccccc} 
Continued & & & & \\
\hline UGL-GGL & 0.021 & 0.001 & 0.062 & 0.081 \\
UGL-FMGL & 0.017 & 0.002 & 0.081 & 0.020 \\
UGL-PZC & 0.012 & 0.003 & 0.098 & -0.032 \\
UGL-TOTAL & 0.024 & 0.002 & 0.096 & 0.082 \\
GGL-FMGL & 0.016 & 0.003 & 0.091 & 0.004 \\
GGL-PZC & 0.011 & 0.004 & 0.106 & -0.042 \\
GGL-TOTAL & 0.022 & 0.003 & 0.102 & 0.065 \\
FMGL-PZC & 0.008 & 0.003 & 0.115 & -0.068 \\
FMGL-TOTAL & 0.019 & -0.001 & 0.104 & 0.031 \\
PZC-TOTAL & 0.014 & 0.002 & 0.122 & -0.012 \\
\hline
\end{tabular}

Table 3. The correlation matrix of the stocks.

\begin{tabular}{ccccccccccc}
\hline \multicolumn{10}{c}{ CORRELATION MATRIX } \\
\hline Cal & 1 & 0.032 & 0.462 & -0.046 & 0.011 & 0.082 & 0.351 & -0.162 & 0.074 & 0.027 \\
EBG & 0.032 & 1 & 0.027 & 0.237 & 0.209 & 0.117 & 0.072 & 0.005 & 0.035 & 0.079 \\
GCB & 0.462 & 0.027 & 1 & 0.020 & -0.010 & 0.285 & 0.341 & 0.262 & 0.145 & -0.145 \\
SCB & -0.046 & 0.237 & 0.020 & 1 & 0.055 & 0.125 & -0.003 & 0.124 & 0.021 & -0.043 \\
HFC & 0.011 & 0.209 & -0.010 & 0.055 & 1 & -0.089 & 0.142 & 0.192 & 0.046 & -0.186 \\
UGL & 0.082 & 0.117 & 0.285 & 0.125 & -0.089 & 1 & 0.147 & 0.165 & 0.236 & 0.083 \\
GGL & 0.351 & 0.072 & 0.341 & -0.003 & 0.142 & 0.147 & 1 & 0.231 & 0.266 & -0.057 \\
FMGL & -0.162 & 0.005 & 0.262 & 0.124 & 0.192 & 0.165 & 0.231 & 1 & 0.129 & -0.171 \\
PZC & 0.074 & 0.035 & 0.145 & 0.021 & 0.046 & 0.236 & 0.266 & 0.129 & 1 & -0.079 \\
TOTAL & 0.027 & 0.079 & -0.145 & -0.043 & -0.186 & 0.083 & -0.057 & -0.171 & -0.079 & 1 \\
\hline
\end{tabular}

assets implies that a certain combination of these assets can reduce the unsystematic risk to zero (Sharpe, 1994). From Table 3, the compounded portfolio has an overall low correlation such that apart from the correlation of an asset by itself which certainly is perfectly correlated, the highest correlation coefficient, 0.462 , occurred between CAL and GCB. A compounded portfolio with an overall low correlation is crucial for investors who aim to diversify in order to eliminate unsystematic risk (Sharpe, 1994). The correlation coefficient between CAL and GCB (0.462) implies that an increase (or decrease) in one of the two will increase (or decrease) in the returns of the other. The correlation coefficient between FMGL and PZC $(-0.171)$ implies that, when the returns of one of them increase, the returns of the other decreases and the reverse is true. There exists a very positive weak correlation (0.005) between FGL and EBG which implies that an increase (or decrease) in the returns of one will only result in a smaller increase (or decrease) in the other. SCB and GGL also had a very weak negative 
correlation $(-0.003)$ between each other implying that an increase in the returns of one will only result in a smaller decrease in the other and the reverse is true.

Having found the optimal portfolio assuming equal weights, this study applied Excel solver to the optimal weights to maximize the returns, minimizing the risk and maximizing the Sharpe Ratio.

From Table 4, the expected returns when trying to maximize returns was achieved with $0.00 \%$ weight to CAL and $100 \%$ weight to GCB with the corresponding returns being $4.27 \%$ and $13.1 \%$ risk. In trying to minimize risk however, the returns and risk expected were $3.77 \%$ and $10.5 \%$ respectively with weights given as $60.79 \%$ for Cal Bank and $39.21 \%$ for GCB. By maximizing the Sharpe ratios, the weights attained were $36.21 \%$ for CAL and $63.79 \%$ for GCB with expected return and risk given as $3.98 \%$ and $10.9 \%$ respectively. The weights at the various columns tells what percentage of an investor's asset should be allocated to the company in question at the optimized level when minimizing risk, maximizing returns and when maximizing the Sharpe ratio. Therefore an investor who will invest in the efficient portfolio (CAL and GCB) and wanting to endure the minimal risk (a risk averse person) of $10.5 \%$ should invest $60.79 \%$ of his assets in CAL and $39.21 \%$ in GCB and he will achieve a $3.77 \%$ returns with a Sharpe ratio of 21.64 monthly. An investor in the efficient portfolio who wants to ascertain the maximum return of $4.27 \%$ monthly regardless of the risk (a risk tolerant person) should invest all (100\% of) his assets in CAL but should expect a $13.13 \%$ risk with a Sharpe ratio of 20.61 monthly. Also an investor in the efficient portfolio who wishes to have a maximum Sharpe ratio of $21.92 \%$ should allocate $36.21 \%$ of his assets to CAL and $63.79 \%$ to GCB and should expect a risk of $10.99 \%$ and a $3.98 \%$ returns monthly which implies an expected annual return and risk to be $47.7 \%$ and $38.1 \%$ respectively (thus, annual return $=0.0398 \times 12=$ 0.477 , annual risk $=0.1099 \times \sqrt{12}=0.381$ ).

\section{Conclusion and Recommendations}

In conclusion, the researcher has been able to estimate the expected returns, standard deviation (risk), skewness and kurtosis of the selected stocks. Based on the Markowitz Mean-Variance analysis, 45 optimal portfolios were generated to

Table 4. Optimal portfolio.

\begin{tabular}{ccccc}
\hline \multicolumn{5}{c}{ OPTIMAL PORTFOLIO } \\
\hline ASSETS & EQUAL WEIGHTS & MAX RETURNS & MIN RISK & MAX SR \\
\hline CAL & 0.5000 & 0.0000 & 0.6079 & 0.3621 \\
GCB & 0.5000 & 1.0000 & 0.3921 & 0.6379 \\
TOTAL WEIGHTS & 1.0000 & 1.000 & 1.0000 & 1.0000 \\
RETURNS & 0.0386 & 0.0427 & 0.0377 & 0.0398 \\
STD. DEV & 0.1061 & 0.1313 & 0.1052 & 0.1099 \\
SR & 0.2164 & 0.2061 & 0.2099 & 0.2192 \\
\hline
\end{tabular}


satisfy the various investor attitudes to risk. A further analysis using excel solver revealed how the risk of the efficient portfolio could be minimized, returns maximized and Sharpe ratios maximized by adjusting the weights of the individual stocks. These results contribute significantly to the existing knowledge on the Ghana Stock Exchange since an average investor can create optimal portfolios to guide him/her in investment decision making.

The study reveals that, stocks in GCB has the highest expected returns of $4.27 \%$ with a $13.13 \%$ risk whiles UGL has the least expected monthly risk of $6.9 \%$ with $2.2 \%$ expected monthly returns. It implies that GCB has an annual expected return of $51.24 \%$ with $45.48 \%$ risk while UGL has the least annual risk of $23.905 \%$ and $26.4 \%$ returns. An uninformed risk averse investor will opt for UGL which has the least expected annual risk of $23.9 \%$ and expect $26.4 \%$ annual returns. The ideal thing to do as an investor is to diversify in order to reduce unsystematic risk. This study put together a two-asset portfolio which yielded 45 portfolio combinations and it was revealed that the combination of GCB and CAL yielded the highest Sharpe ratio of 0.2164 with monthly expected returns and risk of $3.86 \%$ and $10.61 \%$ respectively. The highest Sharpe ratio implies that it is the portfolio which compensates best for the risk taken by the investor and hence the most efficient portfolio. If an investor invests in this portfolio and allocates equal proportions of his assets to the two stocks, he will still achieve a high expected annual return of $46.32 \%$ with the expected annual risk reduced drastically to $36.75 \%$ which emphasizes the importance of diversification. If the risk averse investor is informed and he/she opts for the optimal portfolio with least risk (which is the combination of HFC and UGL) instead of singling out UGL for investment, he/she can expect a monthly return and risk of $1.92 \%$ and $5.2 \%$ respectively with a Sharpe ratio of 6.7 which means that he/she should expect $23.04 \%$ annual expected returns with the expected annual risk reduced to $18.0 \%$ through diversification. Again the study reveals, that risk is minimized when the weights allocated to the individual stocks that make up the portfolio are adjusted by reducing the weight attached to the riskier stock. When the efficient portfolio was optimized using excel solver (from Table 4), it revealed that the monthly expected risk could be reduced to $10.5 \%$ when the investor allocates $60.79 \%$ of his assets to CAL and $39.21 \%$ to GCB but still achieved a monthly $3.77 \%$ returns which implies a minimized expected annual risk of $36.4 \%$ yielding $45.2 \%$ expected annual return. Therefore a risk averse investor who is informed to invest in the efficient portfolio should allocate $60.7 \%$ of his assets CAL and $39.2 \%$ to GCB and enjoy a $45.2 \%$ annual expected returns with a minimal $36.4 \%$ risk which offers a far better prospects to the investor compared to naively investing in only UGL or even in the least risk optimal portfolio (HFC and UGL).

It is therefore recommended that, the most efficient portfolio is the combination of CAL and GCB and therefore investors should opt for it. A risk tolerant investor should allocate all his/her assets to GCB while a risk averse investor can allocate $60.79 \%$ of his/her assets to CAL and $39.21 \%$ to GCB. A risk neutral in- 
vestor should allocate $36.21 \%$ and $63.79 \%$ for his/her assets to CAL and GCB respectively or invest in any of the optimal portfolios constructed by this study.

Since excel can be used to construct more than 45 optimal portfolios, it is recommended that investors can develop portfolios with larger number of stocks to help them take informed investment decisions.

\section{Conflicts of Interest}

The authors declare no conflicts of interest regarding the publication of this paper.

\section{References}

Bawa V. S., Brown S. J., \& Klein R. W. (1979). Estimation Risk and Optimal Portfolio Choice. North-Holland. Amsterdam, NY: North-Holland Pub. Co.

Ceria, S., \& Stubbs, R. A. (2006). Incorporating Estimation Errors into Portfolio Selection: Robust Portfolio Construction. Journal of Asset Management, 7, 109-127. https://doi.org/10.1057/palgrave.jam.2240207

Cornuejols, G., \& Tutuncu, R. (2007). Optimization Methods in Finance. Cambridge: Cambridge University Press.

Fabozzi, F. J. (1999). Equity Portfolio Management. Amazon's Book Store.

Jagannathan, R., \& Ma, T. (2003). Risk Reduction in Large Portfolios; Why Imposing the Wrong Constraints Helps. Journal of Finance, 58, 1651-1684. https://doi.org/10.1111/1540-6261.00580

Markowitz, H. M. (1952). Portfolio Selection. Journal of Finance, 7, 77-91.

Mensah, S. (2008). Securities Markets and Investments (3rd ed.). In A Ghanaian Primer (4th ed., pp. 248-255). Accra: Smartline Limited, C3 Coastal Estates DTD.

Merton, R. C. (1980). On Estimation of Expected Return on the Market: An Exploratory Investigation. Journal of Financial Economics, 8, 323-361. https://doi.org/10.3386/w0444

Mulvey, J. M., \& Erkan H. G. (2003). Decentralized Risk Management for Global P/C Insurance Companies. In Handbook on Finance.

Palmquist J., Pavlo K., \& Uryasev S. (2002). Portfolio Optimization with Conditional Value-at-Risk Objective and Constraints. Journal of Risk, 4, 43-68.

Sharpe, W. F. (1994). The Sharpe Ratio. Journal of Portfolio Management, 21, 49-58. https://doi.org/10.3905/jpm.1994.409501 


\section{Appendix}

$\begin{array}{ll}\text { CAL } & \text { CAL Bank LTD } \\ \text { EBG } & \text { Ecobank Ghana LTD } \\ \text { EIC } & \text { Enterprice Insurance Company } \\ \text { ETI } & \text { Ecobank Transnational Incorporated } \\ \text { GCB } & \text { Ghana Commercial Bank } \\ \text { SIC } & \text { State Insurance Company } \\ \text { HFC } & \text { HFC bank LTD } \\ \text { SCB } & \text { Standard Chartered Bank LTD } \\ \text { TBL } & \text { The Trust Bank LTD } \\ \text { UT } & \text { Unique Trust Bank LTD } \\ \text { MPT } & \text { Modern Portfolio Theory } \\ \text { UNIL } & \text { Unilever Company Limited } \\ \text { FML } & \text { Fan Milk Ghana LTD } \\ \text { PZC } & \text { PZ Cussons Ghana } \\ \text { GGL } & \text { Goil Ghana LTD } \\ \text { UGL } & \text { Uniliver Ghana LTD } \\ \text { TOTAL } & \text { Total Petroleum Ghana }\end{array}$

